\section{salud mental}

Díaz, José Luis

Salvia divinorum: enigma psicofarmacológico y resquicio mente-cuerpo

Salud Mental, vol. 37, núm. 3, mayo-junio, 2014, pp. 183-193

Instituto Nacional de Psiquiatría Ramón de la Fuente Muñiz

Distrito Federal, México

Disponible en: http://www.redalyc.org/articulo.oa?id=58231365002

- Cómo citar el artículo

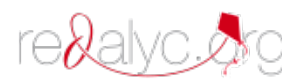

- Número completo

- Más información del artículo

- Página de la revista en redalyc.org

Sistema de Información Científica

Red de Revistas Científicas de América Latina, el Caribe, España y Portugal Proyecto académico sin fines de lucro, desarrollado bajo la iniciativa de acceso abierto 


\title{
Salvia divinorum: enigma psicofarmacológico $y$ resquicio mente-cuerpo
}

\author{
José Luis Díaz'
}

Artículo original

\section{SUMMARY}

In the present paper, the multidisciplinary research on Salvia divinorum and its chemical principles is analyzed regarding whether the ethnobotany, phytochemistry, psychopharmacology, and neuropharmacology of this sacred psychoactive plant and main principle clarify its experienced effects and divinatory uses. The scientific endeavor traverses from the recorded traditional ceremonies and beliefs, continues with the botanical identification, the isolation of active molecules, the characterization of mental and neural effects, the possible therapeutic applications, and impinges upon the mind-body problem. The departure point of this search is ethnopharmacology, and therefore the traditional beliefs, ritual uses, and mental effects of this Mazatec sacred mint recorded during a 1973-1983 field research project are described. A water potion of crushed leaves produced short-lasting light-headedness, dysphoria, tactile and proprioceptive sensations, a sense of depersonalization, amplified sound perception, and increased visual and auditory imagery, but no actual hallucinations. Similar effects were described using questionnaires and are attributable to the diteprene salvinorin $A$, but cannot be explained solely by its specific and potent brain kappa-opioid receptor agonist activity. Some requirements for a feasible classification and mechanism of action of consciousness-altering products are proposed and include the activation of neural networks comprising several neurochemical systems. Top-down analyses should be undertaken in order to characterize such neural networks and eventually allowing to explore the differential ethnic effects. As is the case for other consciousness-altering preparations, a careful and encompassing research on this plant and principle can be consequential to academic undertakings ranging from the mind-body problem and a better understanding of shamanic ecstasy, to the potential generation of analgesic, antidepressant, and drug-abuse attenuating products.

Key words: Consciousness-altering drugs, ethnopharmacology, kappa opioid receptor agonist, Mazatec shamanism, mechanism of action, mind-body problem, Salvia divinorum, salvinorin.

\section{RESUMEN}

En el presente trabajo se considera la investigación multidisciplinaria sobre Salvia divinorum y sus principios químicos activos con el objeto de valorar si la etnobotánica, la fitoquímica, la psicofarmacología y la neurofarmacología de esta planta psicoactiva y su principal producto químico, la salvinorina $A$, clarifican sus efectos mentales y sus usos adivinatorios. Esta labor científica ha trascurrido desde el registro inicial de ceremonias y creencias, ha continuado con la identificación botánica, el aislamiento de los principios químicos, la caracterización de los efectos mentales y cerebrales, las posibles aplicaciones terapéuticas y ha llegado a incurrir en el problema mente-cuerpo. Dado que el punto de partida de esta investigación es la transdisciplina de la etnofarmacología, se retoman aquí las creencias tradicionales, los usos rituales y los efectos mentales de esta menta sagrada de los indios mazatecos tal y como fueron registrados durante un proyecto de campo y laboratorio llevado a cabo entre 1973 y 1983. Un brebaje acuoso de hojas maceradas produjo un breve periodo de ligereza cefálica, disforia, sensaciones táctiles y propioceptivas exacerbadas, un sentido de despersonalización, percepción amplificada de sonidos y un aumento de la imaginación visual y auditiva, pero no verdaderas alucinaciones. Posteriormente otros autores describieron efectos similares usando cuestionarios y eventualmente fueron imputados al diterpeno salvinorina-A, pero no es posible explicar los efectos mentales sólo por la potente actividad agonista del receptor kappa a los opioides encontrada para la salvinorina; de alli el enigma psicofarmacológico. Se proponen algunos requerimientos para una clasificación de drogas que alteran cualitativamente el estado de conciencia e incluyen la activación de redes neuronales que necesariamente comprenden diversos sistemas neuroquímicos y módulos nerviosos. Para caracterizar estas redes será necesario emprender un tipo de investigación top-down, es decir el análisis de imágenes cerebrales obtenidas durante la experiencia psicoactiva analizada mediante un método narrativo, lo cual eventualmente podría permitir la exploración de efectos étnicos diferenciales. Como sucede con otras preparaciones que alteran la conciencia, una investigación rigurosa de la psicofarmacología de esta planta y su principio psicoactivo será relevante a empresas académicas tan diversas como el problema mente-cuerpo, la mejor comprensión del éxtasis chamánico y la posible generación de fármacos analgésicos, antidepresivos y moderadores de la drogadicción.

Palabras clave: Drogas psicoactivas, etnofarmacología, agonista del receptor opioide kappa, chamanismo mazateco, mecanismo de acción, problema mente-cuerpo, Salvia divinorum, salvinorina.

De la Academia Mexicana. Departamento de Historia y Filosofía de la Medicina, Facultad de Medicina, UNAM. Miembro del Comité Editorial de SALUD MENTAL.

Correspondencia: Doctor José Luis Díaz. Cerrada de Cruz Verde 29-B. Colonia Lomas Quebradas. Magdalena Contreras. 10000 México, DF. E-mail: ¡ldiza43@gmail.com

Recibido: 25 de febrero de 2014. Aceptado: 11 de abril de 2014. 


\section{LA VOZ DE LA HOJITA}

"Tienes que cantar la voz de la hojita", me pidió la chamana mazateca durante un ritual en el pueblo de San Bartolomé Ayautla después de darme a beber una amarga infusión acuosa preparada con hojas molidas de Ŝka Pastora, una planta conocida en la ciencia botánica como Salvia divinorum Epling E Játiva-M. Había llegado a Ayautla en 1973 buscando los pasos del investigador independiente y gran erudito R. Gordon Wasson, quien unos diez años antes había descrito el uso ritual y el efecto psicotrópico de esta planta, precisamente en este remoto pueblo fincado al fondo del cañón del río Santo Domingo en la Sierra Mazateca del norte de Oaxaca, México. En aquella época el redescubrimiento de los hongos alucinógenos mexicanos y su estudio por una plétora de eruditos europeos convocados por Wasson era un modelo de investigación, pionero del enfoque metodológico transdisciplinario conocido desde entonces como etnofarmacología.

Yo había regresado poco antes a México, después de haber ampliado mi entrenamiento en psicobiología y psicofarmacología en Boston y decidí emprender un proyecto de investigación sobre plantas psicoactivas mexicanas poco conocidas. El proyecto tenía como objetivo no sólo buscar nuevas herramientas para la investigación psiquiátrica y cerebral sino, precisamente, cultivar una etnofarmacología transdisciplinaria que tomara en cuenta y aplicara el conocimiento milenario de las culturas nativas de mi país. Aquél proyecto y este trabajo representan un esfuerzo por abordar el tema de las plantas psicoactivas desde una aproximación transdisciplinaria en la que los datos etnobotánicos, fitoquímicos, psicofarmacológicos o neuroquímicos no se encuentren simplemente yuxtapuestos, sino que se interrelacionen e integren en la medida de lo posible. Una de las primeras plantas a estudiar fue precisamente la Salvia divinorum. En aquella primera incursión a la sierra mazateca tuve que caminar durante más de seis horas y bajo una llovizna constante por añejas veredas a lo largo del cañón del río de Santo Domingo, para al fin encontrar el pequeño y escondido pueblo de Ayautla.

Tuve la suerte de entrar en contacto con un presidente municipal mazateco inteligente y honesto que me hospedó, inquirió acerca de mi propósito y me mantuvo bajo un agradable y comprensible escrutinio durante algunos días antes de enviarme con una chamana del lugar, una mujer amable y grave de edad madura, llamada Julia Aurelia Palacios, quien iba siempre vestida con un hermoso huipil tradicional. Doña Julia sólo hablaba mazateco, pero su sobrino y aprendiz, Felipe, era bilingüe, de modo que pude entablar una relación con esta familia que, además de pertenecer a un clan tradicional de chamanes, vivía con dificultad y esfuerzo del cultivo y siembra del café de Ayautla, como la mayoría de los habitantes de este pueblo sometido a un cacicazgo tan inicuo como típico de los pueblos indios.
Pronto me enteré de que doña Julia usaba cuatro plantas psicotrópicas tradicionales en sus prácticas curativas y adivinatorias: hongos alucinógenos (Psilocybe spp), semillas de ololiuhqui (Rivea corymbosa), tabaco salvaje o piciete (Nicotiana rustica) y, especialmente, Ŝka* Pastora (Salvia divinorum). Cuando expresé mi interés por la Ŝka Pastora, doña Julia decidió enseñarme sobre la recolección de la planta y su ceremonia como si fuera un aprendiz, ya que no estaba enfermo y tampoco tenía una pregunta específica que ameritase adivinación. Antes de llevar a cabo la primera ceremonia tuve que pasar por un ritual que involucraba ayuno, abstinencia sexual y la recolección de las hojas. Llegado el amanecer con el que terminaba la preparación, Felipe me guió en el ascenso de la empinada montaña del Cañón de Santo Domingo y, después de una extenuante caminata de varias horas, llegamos al lugar sagrado, cuya locación había permanecido secreta hasta ese momento y donde en forma silvestre crecía la Salvia divinorum. La recolección de las hojas de la planta se hizo con respeto y cuidado, pues la planta es considerada parte o manifestación de una figura mítica: la Pastora, una imagen sincrética de la Virgen María. Tuve la fortuna de fotografiar por primera vez en este lugar tan apartado la corola blanca y el cáliz violeta de la flor de esta menta ritual.

La ceremonia tuvo lugar esa noche, en la cabaña de piso de tierra constantemente concurrida en la que vivían doña Julia y su familia. Doña Julia se sentó en un banquillo, seleccionó y contó alrededor de cuarenta hojas por pares y, apoyando los codos sobre las rodillas, las apiló en su mano y las ahumó sobre copal (resina aromática de Burseria). Al mismo tiempo, con una voz monótona y ronca, comenzó a cantar una oración hipnótica y auspiciosa que grabé y posteriormente traduje al español con ayuda de la hija bilingüe del presidente municipal. En esta canción se dirigía a ídolos y fuerzas sobrenaturales del Cañón, a la Santísima Trinidad, a intercesores de la tradición católica como el Señor San Pedro o el Señor San Pablo y al sol como el ser supremo para que me protegieran y me mostraran el camino. He aquí el texto vertido al español de la grabación obtenida el 4 de septiembre de 1974:**

«En el nombre del Padre, del Hijo y del Espíritu Santo, Santísima Trinidad, Viento de la Casa Mazateca, Viento de la Barranca, Agua del Río, que pasen bien por el camino. Señor San Pedro, Señor San Pablo, José Luis, que pasen bien por el camino. (...) Que salga muy bien el Sol y que te cuiden mucho la Santísima Trinidad, Dios Padre, la Madre de Dios. (...) Que salga muy bien el sol y que te cuide mucho cuando viajes por la barranca. Que salga muy bien el Sol y que te cuide mucho; nada le sucederá a nadie. (...) Que salga muy bien el Sol y que te cuide mucho. Que no se rompa una

\footnotetext{
* Ska se pronuncia "shka"; el sonido de la "a" final es más profundo, se encuentra en el cuarto tono del espectro vocálico de la lengua mazateca.

** Díaz, 1976: 145-6. En cursivas lo pronunciado en castellano. El canto tiene un ritmo respiratorio: la chaman hace una inspiración profunda y luego canta hasta terminar la exhalación. Las inspiraciones están marcadas (...) en el texto.
} 
pierna cuando vaya a caminar, que no le dé reuma, que los cuide mucho Dios. Si van a salir por el camino de Jalapa, estos pobrecitos que van a caminar. Dios nos está creando. (...) Que salga muy bien el Sol y que los cuide mucho. Hablo en el nombre del Padre, del Hijo y del Espíritu Santo. Donde está el Río Verde, donde está el Río Frío, si se baña allí que no le dé dolor, que no le pase nada, Señor San Pedro, Señor San Pablo. (...) Que salga muy bien el Sol y que los cuiden mucho el Santo y la Santa. Que no les vaya a pasar algo a lo largo del camino, que lleguen con bien. (...) Están buscando que les dé piciete, que les dé Pastora. Que los cuide mucho la Santísima Trinidad. Que pasen muy bien por todo el pueblo, por las casas que vayan a pasar. En el nombre del Padre, del Hijo, del Espíritu Santo y la Santísima Trinidad.»

Al terminar la invocación, doña Julia molió la planta vigorosamente con las manos en una jícara que contenía agua, hasta que toda la "sangre de la hoja" fue extraída en una poción verde y espumosa de unos $300 \mathrm{ml}$. Me proporcionó la jícara con la instrucción de tomar todo el contenido de una vez y recostarme. El líquido era muy amargo e incluso repulsivo, pero logré tragarlo y retenerlo. Estaba tendido boca arriba en un petate sobre la tierra y, a pesar de que las velas estaban apagadas y no había más iluminación que la trepidante fogata, me pidieron que cerrara los ojos. Doña Julia permaneció callada pero atenta. Yo no sabía qué esperar pero estaba emocionado pues me sentía privilegiado y a salvo bajo el cuidado y la guía de una chamán tradicional tan experimentada como doña Julia.

Pronto tuve sensaciones musculares y escalofríos muy similares a los que acompañan la fiebre y noté que los numerosos sonidos a mi alrededor se escuchaban cerca y amplificados. También noté que las imágenes visuales internas lentamente adquirían relevancia, mientras transitaban por un flujo automático fascinante, dinámico y colorido. Nunca se convirtieron en alucinaciones en el sentido de ser percibidas "allá afuera", en la escena visual externa. Me sentí aturdido, mareado, vagamente entusiasmado, aunque irritable a ratos, extraño, como si no fuera del todo yo mismo. Todos los efectos, que no duraron más de una hora, eran suaves y en cierta medida, decepcionantes por sutiles y efímeros. Tuve que hacerle más visitas a doña Julia y a su amarga bebida de $\hat{S} k a$ Pastora para empezar a aprender el significado de la ceremonia, de los efectos psicotrópicos y de lo que se esperaba de mí cuando, durante las sesiones, ella me alentaba por medio de Felipe a que "cantara la canción de la hojita", como si fuera extraño que no lo hubiera hecho por propia iniciativa.

En la descripción que acabo de hacer de las imágenes que experimenté no me referí a su contenido, es decir de qué trataban, no sólo porque ya casi las he olvidado, sino también porque en ese momento no parecía que fuera algo de trascendencia, pues mi conciencia estaba, por decirlo así, experimentándolas de manera pasiva. Más aún, consecuente con mi cultura y contexto, ingerí esta preparación psicoactiva para tener una experiencia personal y con el ánimo de realizar una observación participante, tal como propone una visión humanística de la antropología con la que yo concordaba. Con el tiempo me di cuenta de que, para los chamanes mesoamericanos, los contenidos mentales que surgen por medio del consumo ceremonial de una planta sagrada son el principal objetivo del ritual porque, según su concepción, a través de la comunión con esta planta un espíritu del consumidor entra en contacto con la figura sincrética y santificada representada por las hojas de Pastora. Como aprendiz, se suponía que debía estar atento a las imágenes y sonidos que aparecían en mi mente y "cantarlos", pero no tenía idea de cómo realizar esto. Durante las últimas ceremonias empecé a concentrarme más en los contenidos de la experiencia y al final hacía un recuento verbal de lo que recordaba de las imágenes. A pesar de que nunca adquirí la pericia necesaria para cantar la voz o la canción de la planta, lo que reporté fue considerado relevante y digno de ser interpretado por mis amables anfitriones.

En 1974, cuando compartí estas experiencias con Gordon Wasson en su casa de Connecticut, él estaba concluyendo un suntuoso libro que incluía grabaciones de María Sabina, chamana mazateca de Huahutla de Jiménez, muy conocida por su mediación. La cuidadosa traducción del mazateco al español y al inglés que la pareja Cowan ${ }^{1}$ hizo de los cantos de María Sabina durante una velada adivinatoria de hongos alucinantes me hizo comprender con mayor claridad qué era lo que se esperaba de mí en las sesiones, pues en dichos cantos María Sabina articulaba poderosamente y de manera inmediata las canciones que surgían en su mente mientras la psilocibina circulaba por sus neuronas. Por supuesto, debo decir de inmediato que el singular estado mental en el que se encontraba María Sabina no era resultado solamente de este crucial hecho neuroquímico, sino también de las circunstancias que los antropólogos denominan set and setting:* una suma de creencias, prácticas y expectativas compartidas por una cultura, además de una vasta práctica personal con plantas psicotrópicas, y la situación ritual y adivinatoria de la velada. Lo que doña Julia me incitaba a hacer y lo que María Sabina hacía en sus cantos, era recitar las "voces"; presumiblemente imágenes auditivas que tenían un contenido cultural particular, las cuales no son tan representativas en los testimonios occidentales de experiencias psicodélicas, como lo son las experiencias visuales. El canto de las voces evocadas por el consumo de plantas psicoactivas durante ceremonias rituales podría ser un punto crucial en el análisis y la interpretación de las variaciones mentales de los efectos según las diversas condiciones culturales. ${ }^{* *}$

\footnotetext{
* Set and setting: lo que el sujeto (historia, personalidad, actitud, etc.) y la circunstancia (tiempo, lugar, compañía, etc.) contribuyen para que ocurra una experiencia particular. A pesar de que Timothy Leary fue el primero en proponer este concepto, su aplicación al uso tradicional de las plantas psicotrópicas fue hecho inicialmente por Marlene Dobkin de Ríos (1975).

** Quiero decir con esto que el registro de las expresiones verbales o cantadas de la experiencia constituyen "textos fenomenológicos" que permiten un análisis narrativo de procesos conscientes (Díaz, Paniagua, Díez Martínez, 1998; Díaz, 2013).
} 
Años más tarde experimenté formas de meditación $V i$ passana, que requerían una concentración similar en cuanto a la detección de los procesos mentales en el presente. La diferencia entre ambas técnicas es que, mientras la meditación introspectiva o Vipassana busca la detección consciente, objetiva y desapegada de contenidos mentales, la práctica chamánica mazateca requiere la expresión de imágenes mentales polisensoriales por medio del canto. Ésta es una habilidad tan demandante en cuanto a la atención y la capacidad de comunicar el contenido que podría ser considerada como una forma de meditación mesoamericana que requiere de un sutil, firme y extendido aprendizaje.

A lo largo de mis visitas a la sierra mazateca en los años subsecuentes pude alcanzar una mayor perspectiva de la práctica adivinatoria y darme cuenta de que convertirse en chamán requería un refinamiento progresivo de las capacidades de atención e introspección necesarias para registrar y expresar los contenidos mentales que tienen lugar en el trance psicotrópico adivinatorio. Me di cuenta, sin embargo, de que no seguiría ese camino y permanecería siendo un investigador académico, interesado en el problema mentecuerpo y la psicobiología, una vocación que me llevó a otras empresas teóricas y empíricas que ahora, muchos años después, me permiten considerar de nuevo la Salvia divinorum desde un enfoque más actual y cuidadoso.

En lo que sigue discurriré acerca de la investigación sobre la $S$. divinorum y sus principios químicos desde un punto de vista que apunta hacia una pregunta psicobiológica central: averiguar si la investigación etnobotánica, química, farmacológica y psicológica sobre esta planta mágica y su principio activo en el cerebro explican sus propiedades fenomenológicas y su uso cultural adivinatorio. Ahora bien, lejos de pretender que una comprensión profunda de los usos y efectos de la planta pueda provenir solamente del análisis científico, considero que la aproximación más útil es penetrar, en la medida de lo posible, en el conocimiento y la información provista por sus consumidores tradicionales, desde una etnología participante, desde las representaciones de los efectos mentales de la planta, los testimonios en primera persona y otros testimonios, así como a partir de los datos objetivos que brindan las diversas ciencias involucradas en la etnofarmacología. A pesar de que el área de estudio propuesta es vasta y seguramente inagotable, una actitud abierta e integrativa debe resultar estimulante y prometedora para el progreso en esta indagación.

\section{ETNOBOTÁNICA Y FITOQUÍMICA}

Hasta donde sabemos, la primera mención de la planta fue hecha en 1939 por el etnólogo J. B. Johnson, quien describe unas hojas de "yerba María" que son machacadas y tomadas en una infusión para fines adivinatorios por los indios mazatecos. ${ }^{2}$ Algunos años después Blas Pablo Reko, pionero de la etnobotánica mexicana, describió en la página 17 de su Mitobotánica zapoteca una planta mágica cuyas hojas producen visiones y que se llama "la hoja de la adivinación". ${ }^{3}$ Siete años después, Robert Weitlaner (1952) describió una ceremonia adivinatoria, conducida por un curandero mazateco, que involucraba el uso de una planta desconocida, y en 1952 el reconocido botánico mexicano Arturo Gómez Pompa recolectó y clasificó la planta como perteneciente al género Salvia, * descrita finalmente en 1962 por Epling y Játiva como una nueva especie, con muestras de herbario que aportó R. Gordon Wasson., 5,

Salvia divinorum Epling $\mathcal{E}$ Játiva- $M$ es una salvia perteneciente a la familia de las mentas o Labiatae. En mazateco recibe los nombres de $\hat{S} k a$ Pastora y Ŝka María Pastora. Ŝka significa hoja en mazateco; por esta razón se llama Hoja de la Pastora y Hoja de María Pastora en español. Los nombres Pastora y María hacen referencia a una representación sincrética de la Virgen María. R. Gordon Wasson propuso que correspondía al Pipiltzintzintli de los antiguos nahuas, pero la información provista en 1772 por una fuente plenamente confiable, el presbítero Antonio Alzate, enciclopédico erudito de la Colonia, indica explícitamente que este nombre fue dado al cáñamo de la marihuana importado a través de la Nao de la China desde Asia por su fibra y que desde entonces fuera utilizada para efectos adivinatorios. ${ }^{7}$

Se trata de una hierba perenne poco común, endémica de la sierra mazateca del Estado de Oaxaca, en México, donde crece en estado natural en los barrancos húmedos y también en otras zonas altas y bastante aisladas. Hoy en día, sin embargo, su cultivo para uso recreativo es amplio en Estados Unidos y Europa. El nombre divinorum le fue dado por los botánicos Epling y Játiva, haciendo alusión a su uso adivinatorio, mencionado por R. Gordon Wasson en 1962. ${ }^{2-4,6}$ Wasson describió la preparación de una poción acuosa hecha con pares de hojas y con el uso de un metate para molerlas. En los años 1970 he publicado extensos estudios etnofarmacológicos del uso ceremonial de la planta, ${ }^{7}$ que he resumido arriba, y más tarde se publicaron datos adicionales por Leander Valdés, ${ }^{8}$ quien me contactó en 1981 para realizar su tesis de Farmacia sobre Salvia divinorum en la Universidad de Michigan. Para evitar la larga caminata de Huautla a Ayautla, conduje a Leander y a su mentor, Ara G. Paul, en coche, desde el este y preguntando a los vecinos localizamos a don Alejandro Vicente, un chamán que vivía en el pueblo de Chichicazapa, cerca de la extensa presa Miguel Alemán. Después de cruzar la presa para recolectar la planta en las lejanas alturas del Cerro Rabón y hacer las preparaciones tradicionales, tuvimos la oportunidad de participar en varios rituales adivinatorios que involucraban

\footnotetext{
* La muestra del Herbario Nacional Mexicano que recolectó Gómez Pompa en 1957 no tenía flores, de modo que no era posible identificar la especie. La ficha de la muestra menciona propiedades alucinógenas, entre los usos de la planta. Véase también la descripción de Gómez Pompa en su sitio: http://gomezpompa.blogspot.mx/2010/11/capitulo-4.html
} 
el uso de la planta, llamada allí Hoja de María. A partir de entonces, Leander Valdés hizo varias contribuciones importantes al conocimiento de la química y la farmacología de la Salvia divinorum.

Durante la década de los años 1970 la Salvia divinorum fue dibujada y descrita en los conocidos tratados de Richard Schultes y Albert Hoffman ${ }^{9,10}$ sobre las plantas sagradas y psicotrópicas. Posteriormente el vínculo íntimo entre estas plantas, su capacidad para inducir episodios extáticos y oníricos y las creencias y prácticas chamánicas en México ha sido documentado en repetidas ocasiones por diversas ciencias etnológicas ${ }^{11}$ e históricas. ${ }^{12}$

Inspirados por las descripciones etnofarmacológicas y las conversaciones personales acerca de la planta, el grupo del fitoquímico Alfredo Ortega, del Instituto de Química de la UNAM, reunió en 1982 suficiente material proveniente de la región mazateca y pronto en su laboratorio aislaron un nuevo diterpeno neo-clerodano al cual nombraron Salvinorina A. ${ }^{13}$ De manera independiente, Valdés aisló dos componentes que fueron llamados Divinorina A y Divinorina B, ${ }^{14}$ pero después confirmó que correspondían a las estructuras de la Salvinorina A y Salvinorina B de Ortega. El uso ritual de la Salvia divinorum en extracto de agua seguía siendo desconcertante, ya que estos diterpenos no eran hidrosolubles y persistía una interrogante con respecto a sus posibles propiedades psicoactivas. Pero este problema merece mayor consideración, como veremos en seguida.

\section{EFECTOS MENTALES DE LA SALVIA DIVINORUM Y LA SALVINORINA A}

En su descripción pionera, Wasson menciona leves efectos visuales de la infusión en agua de Salvia divinorum preparada en los rituales adivinatorios y los compara con una intoxicación inicial con hongos alucinantes del género Psilocybe. ${ }^{6}$ Como mencioné anteriormente, pude participar en ceremonias adivinatorias dirigidas por chamanes mazatecos en Ayautla y Chichicazapa, y describí las creencias, rituales, efectos psicológicos y sobre el comportamiento animal en un libro sobre las plantas psicotrópicas de América Latina publicado en $1976 .{ }^{7}$ En un capítulo sobre plantas psicotrópicas mexicanas menos conocidas, describí que la poción acuosa tradicional producía un mareo de corta duración, fluctuación en el estado de ánimo (entusiasmo, disforia, irritabilidad o malestar general), sensaciones táctiles y propioceptivas de tipo febril, ligeras y esporádicas sensaciones de extrañeza y despersonalización, amplificación de la percepción del sonido y el incremento de imágenes visuales y auditivas, pero no verdaderas alucinaciones. No reporté figuras caleidoscópicas, similares a aquéllas de los alucinógenos "clásicos"; los efectos sensoriales eran principalmente la agudización, intensa aunque de poca duración, de las imágenes visuales y la fantasía, un efecto llamado equívocamente "alucinación".
También en este libro describí el modelo animal que utilizamos para probar los posibles efectos psicodislépticos de los extractos de Salvia divinorum pero, a pesar de que los gatos inyectados con dichos extractos mostraron algunos comportamientos "alucinatorios", como mantener la mirada fija o hacer movimientos de amenaza hacia el espacio vacío, el modelo no era lo suficientemente simple o específico para servir de guía en el aislamiento del principio activo, que más tarde, en 1982, fue logrado con éxito en el laboratorio de Alfredo Ortega. ${ }^{13}$ Valdés reportó que la Salvinorina A y los extractos activos de Salvia divinorum mostraron efectos sedantes no específicos en ratones y algunos cambios en la conducta similares a los producidos por la mezcalina.

En dos trabajos subsecuentes acerca de plantas y drogas psicotrópicas, ${ }^{15,16}$ propuse la siguiente clasificación de los fármacos psicodislépticos, psicodélicos o que alteran cualitativamente la conciencia, de acuerdo a sus efectos mentales y neurológicos, en seis clases:

1. Alucinógenos. Producen fuertes modificaciones cognitivas, afectivas y de la percepción en el contexto de un estado de conciencia amplificado y una estimulación simpaticomimética o ergotrópica. Esta categoría incluye cactos que elaboran mezcalina tales como el peyote (Lophophora williamsii); hongos que contienen psilocibina (Psylocybe spp); inhalables amazónicos (yopo y virola) y otras especies añadidas al brebaje de Ayahuasca (chacruna: Psychotria viridis) que contienen dimetiltriptamina (DMT); y la ergolina indólica sintética conocida como LSD, todos ellos agonistas de los receptores $2 \mathrm{~A}$ de serotonina en el cerebro.

2. Drogas inductoras de trance. Estimulan la producción de imágenes en el contexto de una sedación parasimpática o trofotrópica, aislamiento y apatía. Esta categoría incluye las semillas de ololiuhqui (Rivea corymbosa) que contienen ergolinas y la bebida fermentada de Sinicuiche (Heimia salicifolia) cuyo principio activo se desconoce.

3. Cognodislépticos. Producen estados de ensoñación, incremento de la percepción sensorial que repercute en la imaginería y dificultades cognitivas para recordar o pensar sistemáticamente. Incluye a la marihuana (Cannabis sativa) y la Calea zacatechichi, una planta onirógena utilizada por los indios chontales del sur de Oaxaca, México. Tentativamente coloqué a la Salvia divinorum en esta categoría.

4. Delirantes. Producen alucinaciones, delirio, desorientación, fuertes distorsiones sensoriales, impedimento cognitivo en el contexto de una conciencia obnubilada. Incluye la escopolamina y otros alcaloides tropánicos que se encuentran en diversas plantas de la familia de las solanáceas del Viejo Mundo (Mandragora y Hyosciamus spp) y el Nuevo Mundo (Datura y Brugmansia spp), antagonistas de los receptores muscarínicos del cerebro.

5. Narcóticos. Incluye preparaciones de opio, el látex de diversas papaveráceas, en especial de la adormidera 
(Papaver somniferum) y los derivados de la morfina, su principal principio psicoactivo, en particular la heroína. Estas drogas producen intensas sensaciones de bienestar, euforia y placer en un marco de sedación, letargo, sopor, obnubilación y apatía, así como un poderoso alivio del dolor, el estrés y la ansiedad, ya que actúan como poderosos agonistas de los receptores de endorfinas y encefalinas endógenas, lo cual les confiere una gran capacidad adictiva.

6. Psicodislépticos disociativos como la ketamina, la pentazocina y el óxido nitroso (N2O, el gas de la risa). Producen des-realización (sentimiento de pérdida de la realidad), modificación de la autopercepción y dislocación de las nociones espacio-temporales; conducen, en dosis altas, a la catalepsia y la anestesia disociativa al actuar como antagonistas de los receptores cerebrales de NMDA (Nmetilaspartato o glutamato, un neurotransmisor excitatorio del cerebro).

En esos trabajos hice otras consideraciones acerca de la categoría de los cognodislépticos, donde había colocado tentativamente a la $S$. divinorum. Me pareció que el hecho de que los terpenos no nitrogenados de esta planta resultaran ser psicoactivos fortalecía dicha categorización, ya que el resto de las moléculas psicoactivas de este grupo como el tetrahidrocanabinol (THC) de la marihuana, también eran terpenos no alcaloides. No obstante, la clasificación precisa de los efectos mentales de la $S$. divinorum requería más pruebas para ser determinada, y aún hoy en día, como pronto veremos, esta tarea tiene dificultades.

En contraste con los efectos moderados de los extractos preparados a la manera tradicional, las investigaciones posteriores, realizadas con otras vías de administración, demostraron que la Salvinorina A es una sustancia psicoactiva muy poderosa. La prueba definitiva de que la Salvinorina A es la principal molécula psicoactiva de la Salvia divinorum fue provista por Daniel Siebert, ${ }^{17}$ quien demostró la existencia de efectos mentales con una dosis menor a $0.5 \mathrm{mg}$ del precipitado crudo, lo que significa que este compuesto es el psicoactivo natural más activo que se conoce, casi al mismo nivel de potencia que el LSD. Siebert reportó imágenes visuales caleidoscópicas, cambios en la percepción de la profundidad, apreciaciones sensoriales o estéticas y experiencias de ensoñación creativa. Todos estos efectos tuvieron una duración relativamente corta, de menos de dos horas y con un periodo inicial de latencia también corto, de alrededor de 20 minutos. Las dosis superiores a $1 \mathrm{mg}$ produjeron efectos perturbadores: una pérdida de control sobre la mente y el cuerpo provocó que los sujetos experimentales se movieran sin objetivo; reportaran experiencias extracorporales y posteriormente fueran incapaces de recordar este episodio, una constelación psicofarmacológica similar a la de los psicodislépticos disociativos sintéticos tales como la ketamina y la fenciclidina. Siebert llegó a la conclusión de que la salvinorina A en humanos provoca efectos intensos y de corta duración distintos de aquellos de los alucinógenos "clásicos". Después de este reporte, el investigador independiente Jonathan Ott describió, en una historia bastante detallada y crítica de esta planta, ${ }^{18}$ que la aplicación sublingual de Salvinorina A en acetona y DMSO era altamente psicoactiva, con un umbral de "psicoactividad" entre 250 y 500 mcg y "actividad visionaria" arriba de $1 \mathrm{mg}$.

Los efectos relativamente moderados que se reportaron tras la ingestión del extracto de la planta en agua en la sierra mazateca y los fuertes efectos psicodisociativos del principio activo no son contradictorios. Los efectos relativamente inocuos de las hojas de coca (Erythroxylon coca) masticadas, como se acostumbra en las montañas de los Andes y que actúan como energizantes y estimulantes, son muy distintos, en grado y cualidad, del estado de exaltación intensa y de euforia que se produce inmediatamente después de la inhalación del polvo de cocaína pura. ${ }^{19}$ Las diferentes vías de administración y el material utilizado explican esta brecha en términos de la enorme diferencia de concentración de cocaína en la sangre y su depuración en el cuerpo, por no mencionar un factor más difícil de demostrar: la modulación de la experiencia según la cultura, la finalidad del consumo y la circunstancia.

En el primer congreso denominado "Towards a Science of Consciousness" ("Hacia una ciencia de la conciencia") llevado a cabo en Tucson, donde también presenté un modelo de flujo de la conciencia fenomenológica, ${ }^{20}$ Andrew Weil escribió un interesante capítulo llamado "Pharmacology of Consciousness: A Narrative of subjective experience ${ }^{\prime 19}$ donde analizaba la psicofarmacología de la Salvia divinorum y mencionaba en detalle las imágenes que compartimos Leander Valdés y yo durante una ceremonia con don Alejandro Vicente cuando decidimos mencionar algunos de los contenidos de las imágenes visuales para mostrar, aunque fuera tentativamente, la utilidad de "cantar la voz de la hoja". Vale la pena citar el testimonio en primera persona de Valdés: ${ }^{21}$

Después de alrededor de quince minutos comenzamos a tener visiones. Esta vez yo narré la mía en voz alta, hablando alternadamente en inglés y español, lo que me ayudó a fijarla en mi mente. Díaz habló primero y mencionó algo acerca de flores. Entonces vi imágenes eidéticas que evolucionaron hacia formas de plantas y flores, que después se convirtieron en frutas gigantes y semillas. Sentí que estaba retorciéndome dentro de mi propio cuerpo y que, al mismo tiempo, giraba. Vi una cruz en llamas con dos líneas horizontales, que dejó de arder y comenzó a emitir luz. De pronto, me sentí muy pesado, como si algo me estuviera empujando hacia el fondo de la cama. Me dolían los brazos. Después vi algo que parecía ser una fotografía muy oscura, en blanco y negro. Díaz se disculpó con don Alejandro por nuestra incapacidad para ver las figuras religiosas que el curandero nos había descrito. Mi visión cambió de nuevo a color y vi figuras que rezaban, similares a aquéllas que pueden verse en las iglesias mexicanas. No tenían rostro y su vestimenta estaba cubierta de oro. Apareció la imagen de una cruz con joyas incrustadas. Se convertía lenta y alternativamente en una espada. Al centro de la imagen se podian ver animales, plantas y personas. Si la imagen comenzaba a cambiar o desaparecer, podía concentrarme para hacerla regresar. La última imagen fue la de un castillo que se transformaba en una 
iglesia bizantina. Unas figuras encapuchadas, parecidas a monjes y sin rostro marchaban a su alrededor.

Cuando terminó la ceremonia e íbamos de regreso, Leander Valdés tuvo una intensa experiencia con sentimientos e imágenes marcadamente místicos, que sucedió en el coche y continuó en el hotel donde nos quedamos. Este es su testimonio:

En el cuarto del motel, las imágenes regresaron con más intensidad que nunca. A pesar de que no las describí en voz alta, vi una luz púrpura que pulsaba y cambiaba a una forma de insecto, quizá una abeja o mariposa de noche y después se transformaba en una anémona marina que también pulsaba. Se expandió para convertirse en un desierto lleno de nopales y permaneció así por varios minutos. Durante la primera sesión y a lo largo de la noche todas mis visiones parecían ser una mezcla entre una película muda y una caricatura. Sentí que yo era un observador de estas visiones mudas, más que parte de ellas. Sin embargo, de pronto, me encontré en una pradera extensa con flores de colores brillantes. Acababa de cruzar un arroyo por un pequeño puente de madera. Junto a mí había algo que parecía ser el esqueleto gigante de un modelo de un avión, hecho con tuberías de los colores del arcoiris. El cielo era de un azul brillante y podía verse un bosque en la distancia. Me encontré hablando con un hombre que llevaba una bata blanca brillante y que estaba estrechando mi mano o sujetándola. Era una alucinación impresionante, porque yo creía realmente estar en la pradera. No era como un sueño. Después de un rato regresó el paisaje desértico y me fui quedando dormido lentamente, después de una hora, más o menos. A la mañana siguiente me levanté temprano, sin sentir efectos adversos.

En este expresivo texto fenomenológico en primera persona es importante subrayar que las escenas visuales descritas fueron experimentadas en la oscuridad y con los ojos cerrados, según lo prescrito para la ceremonia, de modo que no están referidas al campo visual externo. Técnicamente no fueron alucinaciones sino imágenes visuales intensificadas que compelían una atención total debido a las circunstancias. Cuando Valdés dice que creía realmente estar en la pradera, se refiere a que sintió que él mismo estaba inserto en otro plano o dimensión, más que a la inserción de objetos en su campo visual. Si no hubiera dicho que esto no era como un sueño, su descripción parecería la de una experiencia onírica o similar al sueño. Evidentemente, la expresión y el análisis de testimonios fenomenológicos producidos bajo el influjo de plantas y drogas psicotrópicas requiere un profuso refinamiento metodológico.

En 2006 se publicó un estudio acerca de los efectos mentales de la Salvia divinorum realizado por un equipo de investigación español del Departamento de Psicología de la Universidad Autónoma de Madrid y el Departamento de Farmacología de la Universidad de Barcelona. ${ }^{22}$ Utilizaron una muestra de 32 consumidores de distintas sustancias psicodélicas para fines recreativos, bajo un protocolo aprobado por un comité de ética. La planta no les fue administrada y los efectos subjetivos fueron asentados en un testimonio en retrospectiva, por medio de cuatro cuestionarios, tales como la versión en español de la HRS o Hallucinogen Rating Scale, de 71 preguntas, y el Altered State of Consciousness Questio- nnaire (cuestionario de estados alterados de conciencia), de 72 preguntas. La descripción de estos efectos fue reportada según una serie de variables categóricas. En promedio, los efectos fueron considerados como intensos y breves, con una duración de menos de quince minutos. Los principales efectos reportados fueron modificaciones de "tipo psicodélico" sobre la percepción visual, así como sensaciones anímicas y somáticas, la modificación de la percepción de uno mismo y de la realidad. La intensa desrealización fue considerada característica de la Salvia, mientras que otros efectos psicológicos fueron considerados similares a los de los "psicodélicos clásicos". A pesar de que los autores reconocen la naturaleza preliminar de sus resultados, esta investigación apunta hacia la necesidad de evaluar la naturaleza fenomenológica de los efectos psicoactivos no sólo de la Salvia divinorum, sino también de otras moléculas psicoactivas, plantas o preparados.

Los efectos mentales de la planta y su principio activo son una novedad psicofarmacológica y también un enigma debido a los tres tipos de respuestas que han sido reportados de manera consistente:

1. Intensificación de la imaginería visual y auditiva, experiencias oniroides similares a los sueños y un estado de alerta, parecidos en cierto modo a las etapas iniciales de una experiencia con "alucinógenos clásicos" que muestran actividad como agonistas de los receptores de serotonina y dopamina. Probablemente los contenidos de las imágenes visuales difieren en que en los alucinógenos son más caleidoscópicas y en la Salvia, más fantasiosas y oníricas, pero esto necesitaría una mayor especificación.

2. Extrañeza, desrealización, despersonalización, modificación de la autopercepción, dislocación espacio-temporal y experiencias extracorporales, semejantes a los efectos de los psicodislépticos disociativos que muestran actividad en el receptor de NMDA.

3. Disforia, sensaciones "somáticas" tales como hipo o hiperalgesia y sensaciones propioceptivas de tipo febril que sugieren la participación de receptores opioides.

La principal tarea psicofarmacológica sería producir hipótesis justificadas y comprobables acerca de los fundamentos neurológicos de estos efectos mentales. El descubrimiento inesperado de que la Salvinorina A es un ligando fuerte y específico del receptor opioide kappa, ${ }^{23} \mathrm{y}$ la intensa actividad en el campo de la investigación farmacológica que tuvo lugar a partir de este descubrimiento, aportan información valiosa para concebir hipótesis factibles acerca de estos fundamentos.

\section{FARMACOLOGÍA DE LA SALVINORINA A, AGONISTA DEL RECEPTOR OPIOIDE KAPPA}

En su investigación sobre la psicofarmacología de la Salvinorina $\mathrm{A}$, Siebert ${ }^{17}$ reportó que no había una interacción 
significativa de este compuesto con 42 receptores cerebrales, que incluían receptores de monoaminas, aminoácidos y otros neurotransmisores. Esta incapacidad de unirse a receptores del Sistema Nervioso Central era un obstáculo para explicar los efectos psicológicos de una molécula cuyos efectos psicoactivos ya habían sido probados. Sin embargo, pocos años después Roth et al. ${ }^{23}$ describieron el hecho inesperado de que la Salvinorina A es un agonista altamente selectivo y de rápida acción del receptor opioide kappa. La Salvinorina A resultó ser un ligando kappa sorprendente, puesto que es una molécula de diterpeno, carente de nitrógeno, que muestra una alta selectividad para este receptor y virtualmente ninguna afinidad por otros receptores de las drogas psicoactivas. Muy pronto después de este descubrimiento, Chavkin et al. ${ }^{24}$ demostraron que la Salvinorina A es un agonista kappa más eficaz que los agonistas tradicionales de estos receptores y también más efectivo que la dinorfina 1-13 para activar los receptores kappa, lo cual indica que la Salvinorina A es el agonista kappa no péptido y de origen natural más eficaz conocido.

Los receptores opioides kappa son uno de cuatro grupos de receptores cerebrales que se unen a derivados del opio, ${ }^{*}$ en este caso especialmente los péptidos opioides endógenos de 32 aminoácidos conocidos como dinorfinas. ${ }^{26} \mathrm{~A}$ pesar de que los agonistas de opioides kappa tienen propiedades analgésicas que supuestamente carecían de los efectos indeseados que tiene la morfina, Pfeiffer et al. ${ }^{27}$ reportaron que el agonista kappa benzomorfano MR2033 tenía efectos disfóricos y "psicotomiméticos" similares a los de la feniciclidina. Las dinorfinas, que son abundantes en el cerebro y particularmente en el hipotálamo, modulan la respuesta al dolor de una manera intrincada, ya que algunas veces muestran propiedades analgésicas y otras estimulan el dolor. También muestran efectos que contrarrestan los de la cocaína, que se atribuyen a su capacidad de inhibir la liberación de dopamina; están vinculadas a la disforia inducida por estrés; incrementan el apetito y alteran la termorregulación. Dado que la Salvinorina A comparte la afinidad de los receptores opioides kappa con las dinorfinas, no es sorprendente que muchos de los efectos reportados de la Salvia divinorum también se hayan encontrado en estos péptidos, incluyendo su posible efecto antidepresivo. De hecho, la unión inusual de la Salvinorina A con los receptores kappa como agonista abre la posibilidad de que ésta pueda convertirse en una sustancia de interés en términos de las funciones y trastornos que involucran la actividad de estos receptores. En un estudio de comportamiento en peces ze$\mathrm{bra}^{28}$ la Salvinorina A inducía un nado acelerado y un efecto que asemejaba un "trance" con dosis de 5 y $10 \mu \mathrm{g} / \mathrm{kg}$. Un tratamiento previo con antagonistas kappa o antagonistas canabinoides tipo 1 bloqueaba los efectos. El compuesto

* Es interesante notar la afinidad de los receptores opioides sigma con la dimetiltriptamina (DMT). ${ }^{25}$ también hizo que aumentara el tiempo que pasaban en el compartimento asociado a la droga, lo que indica que ésta tuvo los efectos placenteros o de recompensa que involucran la activación de los receptores opioides kappa y los receptores cannabinoides CB1.

En su revisión de las propiedades antinociceptivas de la Salvinorina A, McCurdy et al. ${ }^{29}$ mencionan que los agonistas de opioides kappa han sido usados en el tratamiento del dolor, la drogadicción, los trastornos alimenticios y la depresión. El hecho de que los agonistas de receptores opioides kappa atenúan algunas de las alteraciones neuroquímicas y de comportamiento provocadas por el abuso de drogas resulta particularmente interesante por su potencial terapéutico. Los agonistas kappa reducen el consumo de cocaína auto-administrada en primates no humanos y Potter et $a .^{30}$ reportaron que la administración repetida de Salvinorina A disminuye los efectos potenciadores de recompensa en una prueba con cocaína (cocaine challenge) y en un paradigma de autoestimulación intracraneal. Los autores reportaron que algunas evidencias con respecto a los efectos de los agonistas kappa en los sistemas de recompensa del cerebro son contradictorias y propusieron que posiblemente la interacción entre la activación de los receptores kappa y la respuesta de recompensa que provoca la droga involucra una combinación de procesos opuestos y mecanismos de reforzamiento negativo.

Los posibles efectos antinociceptivos de la Salvinorina A también han sido investigados. A pesar de que McCurdy et al. ${ }^{29}$ demostraron que este diterpeno es un potente ligando del receptor opioide kappa que puede ser un analgésico de acción veloz en administración sistémica, también advierten que su utilidad clínica es limitada por su corta duración y por los efectos psicoactivos que se producen con dosis similares. Su propuesta es que los análogos estructuralmente relacionados podrían tener un efecto analgésico con mayor duración y sin esta actividad psicotrópica indeseada.

\section{EL POSIBLE "MECANISMO DE ACCIÓN", UN RETO RELEVANTE PARA EL PROBLEMA MENTE-CUERPO}

El concepto de "mecanismo de acción" en farmacología es una propuesta intrínsecamente reduccionista pues pretende explicar los efectos clínicos de una droga en términos de sus efectos moleculares sobre receptores específicos y otras funciones bioquímicas localizadas en tejidos y organismos relevantes para esos efectos. En el caso de las plantas psicoactivas el concepto está necesariamente relacionado a aquél de "principio activo", la molécula o moléculas responsables de sus efectos mentales en términos de su actividad neurofarmacológica en el nivel molecular. Por ejemplo, la mezcalina es reconocida como el principio activo del peyote (Lophophora williamsii) y su mecanismo de acción se atribuye a la 
actividad de este alcaloide como agonista de los receptores postsinápticos de serotonina $2 \mathrm{~A}$ en el cerebro, una propiedad que comparte con otros alucinógenos como la psilocibina, la DMT y el LSD. Ésta es una descripción bastante precisa, pero difícilmente puede considerarse completa. Uno de los datos faltantes es un entendimiento correcto de los pasos intermedios entre un síntoma, por ejemplo, una modificación perceptiva, cognitiva o emocional, y una interacción biomolecular. El entendimiento de estos fenómenos en sus diferentes niveles no constituiría solamente un "mecanismo de acción" científico exitoso, sino que dilucidaría nada menos que el recalcitrante problema mente-cuerpo. En realidad la idea de que los alucinógenos podrían ser un instrumento para abordar y quizás resolver el problema mente-cuerpo fue anticipada no tanto por científicos o filósofos sino por los renombrados poetas y pensadores Aldous Huxley ${ }^{31}$ y Octavio Paz. ${ }^{32}$

Pero en el caso de las drogas psicoactivas nos encontramos con la desconcertante brecha que se abre entre un correlato neurológico de la conciencia y la experiencia subjetiva, dos piezas diferentes de información que se encuentran y describen en primera y en tercera personas respectivamente. La brecha en el caso del "mecanismo de acción" de la Salvia divinorum o de otras plantas psicoactivas podría ser un obstáculo para la explicación convincente de los efectos mentales, incluso si se hubiera logrado tener una descripción completa de los efectos de sus principios neuroactivos en todos los niveles del funcionamiento cerebral.

La ventaja de las drogas que alteran la conciencia es que puede obtenerse una descripción de su mecanismo de acción a un alto nivel de integración funcional por medio de la combinación de técnicas de imagen cerebral (tercera persona) y el uso de herramientas fenomenológicas calibradas durante una experiencia psicotrópica supervisada cuidadosamente (primera persona). Una correlación obtenida de manera consistente marcaría empíricamente una correspondencia entre la información neurológica y el efecto mental. Esta correlación psicofísica permitiría la exploración de mecanismos neurológicos de alto nivel en términos reductivos pero no eliminatorios. El siguiente paso hacia esta difícil meta sería dilucidar los pasos que están entre la propiedad de la Salvinorina A como agonista del receptor opioide kappa y los efectos mentales conocidos de la planta: ¿cuáles serían estos pasos intermedios?

Las funciones estructurales y neuropsicológicas del cerebro están ordenadas jerárquicamente en seis niveles de acción, a grandes rasgos: molecular, celular, intercelular, modular, orgánico y organísmico. ${ }^{33}$ Como sucede con muchos compuestos psicoactivos, la información de los efectos mentales y conductuales de la Salvia divinorum en los niveles orgánico y organísmico es limitada; en cambio, la información es más detallada y confiable en cuanto a las interacciones moleculares y celulares de la Salvinorina A y las neuronas que tienen receptores kappa. A pesar de la brecha, se puede inferir o proponer justificadamente un vínculo entre los niveles intermedios de la explicación diciendo, por ejemplo, que los efectos disfóricos tanto de la planta como del principio activo podrían estar relacionados con el agonismo selectivo del receptor kappa pues la dinorfina, el ligando endógeno de estos receptores opioides, también produce estos efectos. Incluso en este caso, una explicación más completa requeriría discernir qué redes neuronales son las responsables, en los niveles intermedios, de los efectos disfóricos.

Otro enigma psicofarmacológico que requiere la explicación de pasos intermedios es que esta planta comparte con los alucinógenos una notable intensificación de la imaginería sensorial y otros efectos de ampliación de la conciencia que no son explicados exclusivamente por el agonismo del receptor kappa. En este contexto es importante considerar otros hechos neurofarmacológicos importantes, por ejemplo, que el núcleo dorsal del rafé, uno de los principales sitios serotoninérgicos del cerebro, tiene también una alta densidad de receptores kappa. ${ }^{34}$ Este tipo de coyunturas clínicas y neuroquímicas requieren una explicación del mecanismo intercelular, pues probablemente existen redes cerebrales que reúnen las neuronas y receptores de, al menos, dopamina, serotonina y opioides, que podrían ser de una manera directa e integral responsables de los llamados efectos "psicodélicos" en un nivel intercelular. Actualmente no se sabe cuáles serían estos circuitos, cómo están conectados, cuál es el papel de cada neurotransmisor y cada tipo de receptor dentro de la red, dónde está ubicado el sistema, cómo se activa y, más difícil aún, cómo engendra o se corresponde con el proceso mental y conductual involucrado en el efecto clínico. La labor de encontrar y unir las piezas moleculares del rompecabezas es un procedimiento que va de lo particular a lo general.

El procedimiento de inferencia por medio de herramientas neurofarmacológicas está justificado y ha avanzado, pero también es muy difícil pues no hay modelos de redes neuronales que sean realistas y viables para apoyar esta indagación. Para consolidar una explicación más integral de los efectos psicoactivos, sería interesante emplear una estrategia de lo general a lo particular basada en la obtención de imágenes del cerebro bajo los efectos de la planta y sus principios activos para localizar los módulos que están involucrados, por medio de resonancia magnética funcional o tomografía por emisión de positrones.

El enfoque molecular y celular ha sido por mucho tiempo la principal herramienta para diseñar drogas psiquiátricas efectivas, como sucede en el caso de las sustancias consideradas antidepresivas, porque muestran la capacidad de bloquear la recaptación de las monoaminas cerebrales que ejercen de neurotransmisores. Esta aproximación está lejos de ser infalible pero, a falta de un modelo de mecanismo de acción alternativo, sigue siendo utilizada y se justifica en términos pragmáticos. En este marco se ha trabajado con la Salvia divinorum y sus salvinorinas y eventualmente con 
componentes químicamente modificados para crear agentes analgésicos, antidepresivos o que contrarresten los efectos de la adicción.

Hay otros retos metodológicos que superar en términos de la relación psicofísica entre los procesos cerebrales y los procesos conscientes. El balance en el presente entre las herramientas neurológicas y las psicológicas está claramente inclinado a favor de las neurociencias, tecnológicamente tan refinadas, y de las técnicas e instrumentos relativamente escasos que puedan discernir de manera confiable los efectos mentales de las sustancias psicotrópicas. Las herramientas clínicas para realizar entrevistas fenomenológicas, desarrolladas por los psiquiatras europeos clásicos, fueron usadas entre otros por el profesor Don Dionisio Nieto, mi maestro inicial y mentor, desde los años 1960, para describir cuidadosamente los efectos mentales del hongo Stropharia cubensis $^{35}$ y la psilocibina. ${ }^{36}$ Sin embargo estos procedimientos han sido marginados por cuestionarios estandarizados que ahora son difíciles de aplicar, debido a que muchas de las plantas y drogas están controladas pues son categorizadas, muchas veces erróneamente, como sustancias adictivas o potencialmente peligrosas. La viabilidad de herramientas fenomenológicas bien calibradas que aporten una perspectiva en primera persona ha sido revisada y redefinida por la neurofenomenología de Francisco Varela ${ }^{37}$ y por el método narrativo que hemos propuesto repetidamente. ${ }^{33,38}$

El campo de la psicofarmacología clínica de las drogas que alteran la conciencia es problemático. Hay todavía una considerable confusión con respecto a los perfiles de los efectos mentales de los diferentes compuestos, de tal forma que términos o expresiones como: psicodisléptico, psicodélico, visionario, psicotomimético, conciencia alterada, alucinógeno, enteógeno, narcótico y estupefaciente, entre otros, son usados sin un consenso realmente establecido e incluso, indistintamente. Con una definición cuidadosa y justificada, muchos de estos términos serían útiles para referirse a significados restringidos, específicos y comprensibles dentro del amplio espectro del efecto psicoactivo. Es necesario tener herramientas fenomenológicas confiables para caracterizar los efectos mentales y los perfiles de las diferentes drogas y así tipificar su perfil psicológico y correlacionar efectos mentales bien establecidos con mecanismos de actividad cerebral, específicamente en los niveles más altos de integración, donde la conciencia probablemente emerge junto con una posible función transmodular, similar a un enjambre o parvada de actividad neural. ${ }^{20,33}$

Si estos requisitos son de por sí difíciles de cumplir, es aún más complicado explicar los diversos efectos mentales que tiene la misma planta o droga en personas y circunstancias de diferentes culturas. ${ }^{39}$ Un enfoque etnográfico-neurocientífico aplicado al estudio comparativo de los efectos de las plantas sagradas en diferentes sujetos podría arrojar algo de luz sobre el papel que cumplen los sistemas de creencias, el set and setting y otras variables culturales en la determina- ción de los contenidos de la conciencia. Quizá de esta manera sea posible abordar y entender el interés existencial e incluso la fascinación que la ingesta tradicional y moderna de estas notables plantas y sus compuestos ha ejercido en sus usuarios humanos a lo largo de milenios. Este interés no sólo ha producido, refinado y conservado las prácticas chamánicas en docenas de culturas tradicionales en las Américas, sino que también jugó un papel importante en la renovación de ideas y actitudes provocada por la revolución de la cultura occidental durante los años 1960 y sigue siendo un interés genuino entre diversos grupos hoy en día en países y sociedades desarrollados. Esta vía para enfrentar el problema mente-cuerpo, en relación con estados de conciencia inusual pero aprehensible y sus correlatos neurológicos, sólo podría ser efectiva si la investigación responsable y meticulosa es apreciada y fomentada.

\section{RECONOCIMIENTOS}

Durante el proyecto inicial sobre la etnofarmacología de la Salvia divinorum y otras plantas alucinógenas mexicanas, entonces poco conocidas, entre 1973 y 1983, tuve el gran privilegio de recibir los consejos y la amistad de R. Gordon Wasson (1898-1986), y también de Richard Evans Schultes (1915-2001) del Museo Botánico de la Universidad de Harvard (Botanical Museum of Harvard University); de Efrén del Pozo (1907-1979) y Alfredo López Austin, de la Universidad Nacional Autónoma de México, y de Salomón Nahmad, entonces director del Instituto Nacional Indigenista. Agradezco al profesor Ara Paul la lectura y corrección de un manuscrito previo en inglés. Agradezco también a Héctor Vargas Pérez, Aurelia Cortés y Vida Ortega Font por su ayuda en la preparación de este manuscrito.

\section{REFERENCIAS}

1. Wasson RG, Cowan G, Cowan F, Rhodes W. María Sabina and her mazatec mushroom velada. New York: Harcourt Brace Jovanovich; 1974.

2. Johnson JB. The elements of mazatec witchcraft. Göteborg: Etnografiska Museum Ethnologiska Studier ed.; 1939.

3. Reko BP. Mitobotánica zapoteca. Edición particular General León 9; 1945.

4. Weitlaner RJ. Curaciones mazatecas. Anales del Museo Nacional de México 1952(4):279-285.

5. Epling C, Játiva-M CD. A new species of Salvia from Mexico. Botanical Museum Leaflets Harvard University 1962;20(3):75-76.

6. Wasson RG. A new Mexican psychotropic drug from the mint family. Botanical Museum Leaflets Harvard University 1962;20(3):77-84.

7. Diaz JL. Etnofarmacología de plantas alucinógenas latinoamericanas. En: Diaz JL (ed). Etnofarmacología de plantas alucinógenas psicotrópicas latinoamericanas. Mexico: Cuadernos Científicos del Centro Mexicano de Estudios en Farmacodependencia; 1975; Págs. 135-201.

8. Valdes LJ, Diaz JL, Paul AG. Studies of salvia divinorum (lamiaceae), an hallucinogenic mint from the sierra mazateca in oaxaca, central mexico. Economic Botany 1983;41(2):283-291.

9. Schultes RE, Hofmann A. Plants of the gods: Origins of hallucinogenic use. New York: A. van der Marck Editions; 1987.

10. Schultes RE, Hofmann A. The botany and chemistry of hallucinogens. Springfield, Ill.: Thomas; 1980.

11. Fagetti A. Iniciaciones, trances, sueños: Investigaciones sobre el chamanismo en México. México: BUAP, Instituto de Ciencias Sociales y Humanidades "Alfonso Velez Pliego"; 2010. 
12. De la Garza M. Sueño y alucinación en el mundo nahuatl y maya. México: illustrated ed. UNAM; 1990.

13. Ortega A, Blount JF, Manchand PS. Salvinorin, a new transneoclerodane diterpene from salvia divinorum (labiatae). J Chem Soc Perkin Trans1982;1:2505-2508.

14. Valdes III LJ, Butler WM, Hatfield GM, Paul AG et al. A psychotropic terpenoid, and divinorin $B$ from the hallucinogenic mexican mint, salvia divinorum. J Org Chem 1984;49(24):4716-4720.

15. Díaz JL. Ethnopharmacology of sacred psychoactive plants used by the indians of Mexico. Annu Rev Pharmacol Toxicol 1977;17(1):647-675.

16. Díaz JL. Ethnopharmacology and taxonomy of Mexican psychodysleptic plants. J Psychoactive Drugs 1979;11(1-2):71-101.

17. Siebert DJ. Salvia divinorum and salvinorin A: New pharmacologic findings. J Ethnopharmacol 1994;43(1):53-56.

18. Ott J. Ethnopharmacognosy and human pharmacology of salvia divinorum and salvinorin A. Curare 1995;18(1):103-129.

19. Weil A. Pharmacology of consciousness: A narrative of subjective experience. En: Hammeroff SR, Kaszniak AW, Scott AC (eds). Toward a science of consciousness. Cambridge, Massachusett: MIT Press; 1996; Págs. 677-689.

20. Diaz JL. The stream revisited: A process model of phenomenological consciousness. En: Hammeroff SR, Kaszniak AW, Scott AC (eds). Toward a scientific basis of consciousness. Cambridge, Massachusett: MIT Press; 1996; Págs. 713-724.

21. Valdés LJ. Salvia divinorum and the unique diterpene hallucinogen, salvinorin (divinorin) A. J Psychoactive Drugs 1994;26(3):277-283.

22. González D, Riba J, Bouso JC, Gómez-Jarabo G et al. Pattern of use and subjective effects of salvia divinorum among recreational users. Drug Alcohol Depend 2006;85(2):157-162.

23. Roth BL, Baner K, Westkaemper R, Siebert D et al. Salvinorin A: A potent naturally occurring nonnitrogenous kappa opioid selective agonist. Proc Natl Acad Sci USA 2002;99(18):11934-11939.

24. Chavkin C, Sud S, Jin W, Stewart J et al. Salvinorin A, an active component of the hallucinogenic sage salvia divinorum is a highly efficacious kappa-opioid receptor agonist: Structural and functional considerations. J Pharmacol Exp Ther 2004;308(3):1197-1203.

25. Fontanilla $D$, Johannessen $M$, Hajipour AR, Cozzi NV et al. The hallucinogen $\mathrm{N}, \mathrm{N}$-dimethyltryptamine (DMT) is an endogenous sigma-1 receptor regulator. Science 2009;323(5916): 934-937.
26. Knoll AT, William AAC. Dynorphin, stress, and depression. Brain Res 2010;1314(0):56-73.

27. Pfeiffer A, Brantl V, Herz A, Emrich HM. Psychotomimesis mediated by kappa opiate receptors. Science 1986;233(4765):774-776.

28. Braida D, Limonta V, Pegorini S, Zani A et al Hallucinatory and rewarding effect of salvinorin $A$ in zebrafish: Kappa-opioid and cb1-cannabinoid receptor involvement. Psychopharmacology (Berl) 2007;190(4):441-448.

29. McCurdy CR, Sufka KJ, Smith GH, Warnick JE, Nieto MJ. Antinociceptive profile of salvinorin $A$, a structurally unique kappaopioid receptor agonist. Pharmacol Biochem Behav 2006;83(1):109-113.

30. Potter DN, Damez-Werno D, Carlezon WA, Cohen BM et al. Repeated exposure to the k-opioid receptor agonist salvinorin A modulates extracellular signal-regulated kinase and reward sensitivity. Biol Psychiatry 2011;70(8):744-753.

31. Huxley A. The doors of perception: And heaven and hell. Vintage Digital; 2010.

32. Paz O. Conocimiento, drogas, inspiración. En: Obras completas, volumen 2: Excursiones/Incursiones: dominio extranjero. Mexico: Fondo de Cultura Economica; 1994; págs. 238-272.

33. Díaz JL. La conciencia viviente. Mexico: Fondo de Cultura Economica; 2007.

34. DePaoli AM, Hurley KM, Yasada K, Reisine T et al. Distribution of kappa opioid receptor mrna in adult mouse brain: An in situ hybridization histochemistry study. Mol Cell Neurosci 1994;5(4):327-335.

35. Nieto D. Psicosis experimentales. Efectos psíquicos del hongo stropharia cubensis de oaxaca. Neurol Neurocir Psiquiat 1959;1:6-12.

36. Nieto D. Psicosis experimentales con psilocibina. Neurol Neurocir Psiquiat 1962;3:140-146.

37. Varela FJ. Neurophenomenology: A methodological remedy for the hard problem. J Conscious Stud 1996;3(4):330-349.

38. Díaz JL, Paniagua R, Diez-Martínez E. El texto fenomenologico como objeto de análisis de procesos conscientes. Salud Mental 1998;21(1):14.

39. Dobkin de Rios M. Una teoría transcultural del uso de los alucinógenos de origen vegetal. Am Indíg 1977;37(2):251-304.

Artículo sin conflicto de intereses 